\title{
JUSTIFICATION OF THE RHEOLOGICAL MODEL OF PROCESS OF PLASTIC MATERIAL INJECTION BY THE ROLLERS
}

Katarzyna Szwedziak ${ }^{\mathrm{a}}$, Igor Stadnyk ${ }^{\mathrm{b}}$, Sergey Golyachuk ${ }^{\mathrm{c}}$, Żaneta Grzywacz ${ }^{\mathrm{d}}$

${ }^{a}$ Department of Biosystem Engineering Opole University of Technology, Poland, ORCID 0000-0003-1104-5143

b Department of Food Biotechnology and Chemistry, Ternopil Ivan Puluj National Technical University, Ukraine, ORCID 0000-0003-4126-3256

c Department of Food Biotechnology and Chemistry, Lutsk National Technical University, Ukraine, ORCID 0000-0002-4835-8154

d Department of Biosystem Engineering Opole University of Technology, Poland, ORCID 0000-0001-6278-6924

*Corresponding author: e-mail: z.grzywacz@po.opole.pl

\begin{tabular}{ll}
\hline ARTICLE INFO & ABSTRACT \\
\cline { 2 - 2 } $\begin{array}{l}\text { Article history: } \\
\text { Received: August } 2019 \\
\begin{array}{l}\text { Received in the revised form: } \\
\text { September 2019 }\end{array} \text { Accepted: September } 2019\end{array}$ & $\begin{array}{l}\text { It is justified thatproblems related to the changes in structural and me- } \\
\text { chanical properties of plastic material and influence of structural ele- } \\
\text { ments of equipment and modes of implementation of the for-mation } \\
\text { process on them are considered detail, taking into account empirical } \\
\text { data, theoretical dependencies and results of physical experiments. It } \\
\text { Key words: } \\
\text { three-phase medium, } \\
\text { rollers, } \\
\text { rheology, } \\
\text { shift deformation, } \\
\text { plastic material, } \\
\text { gas phase }\end{array}$ \\
$\begin{array}{l}\text { grooves on a structured dispersion plastic material in the node of injec- } \\
\text { tion of the molding machine, internal shear, and shearing deformation } \\
\text { have a preponderant value. Accordingly, the productivity of machines } \\
\text { is determined mainly by the structural parameters of the working bodies } \\
\text { geometry, kinematics, and contact area. It is shown that increasing the } \\
\text { pressure in the plastic material causes a decrease in its volume, but the } \\
\text { relationship between pressure and volume has a nonlinear character. It } \\
\text { has been established that regardless the variety of flour from which the } \\
\text { plastic material was prepared for bagels, its moisture content and the } \\
\text { duration of fermentation reduced viscosity of the effective plastic ma- } \\
\text { terial along with the increase of the shear stress. The paper describes } \\
\text { the refined rheological model of the Bingham body deformation, which } \\
\text { develops instantaneously, and the velocity of the common elastic defor- } \\
\text { mation in the dough is a simultaneous function of stresses and temper- } \\
\text { atures, which are close to exponential ones. }\end{array}$ \\
\hline
\end{tabular}




\section{Introduction}

Lately, there have been ongoing works around the world on the development and improvement of processing lines for production of flour confectionery consisting of several semifinished products with different flavors. Manufacturers face rather serious economic problems. They are connected with both decrease in the quality of raw materials used for manufacturing of products andhigh energy intensity of the baking and confectionery industry and with irrational organization of the technological process. A question concerning the need to intensify production, implementation of new techniques and technologies has been repeatedly raised. This is due to the fact that existing variants of equipment are not always acceptable due to the cost of equipment, differences in consumers' preferences, who are mostly conservative and discontinue the use of traditional products made of natural products by the twophase scheme.

In scientific works devoted to the improvement of traditional technologies of baking and confectionery products production, increasing its quality, creating energy and resource-saving productions, a considerable attention is paid to the stage of formation of plastic material semifinished products. In studying the work of existing technological equipment in the food industry, as well as in the design of its new samples, there are numerous processes that are difficult to describe by existing methods of the mathematical apparatus. These processes include the process of separation, formation. It is difficult to imagine and describe a behavior of viscous fluid in the working chamber, and thus to obtain a distribution of velocities at all points of the volume, the intensity of dissipation of kinetic energy, power indices of specific work and power output.

Problems of changing the structural and mechanical characteristics of plastic mate-rial and the influence of the structural elements of equipment and modes of imple-mentation of the formation process on them are considered in detail, taking into account empirical data, theoretical dependencies and the results of physical experiments. When creating the equipment for formation of the environment, the preference is given to the method of smooth suction, pumping, and injection, which makes it possible to intensify the production process and obtain a wide range of products. Therefore, the main focus is on the design of the injection of a molding machine node and substantiation of operating modes at which receipt of highquality plastic material semi-finished products with reduced energy costs, as well as obtaining mathematical dependencies suitable for engineering calculations of energy costs for the process implementation is ensured.

Therefore, creation of recommendations for the development of equipment for mechanized production while formation by the mentioned method is an urgent problem for the confectionery industry.

\section{Analysis of the latest studies}

The study of the process on how working bodies effect the structural and mechanical properties of the elastic-plastic-viscous medium when the deformation velocity is changed, which is practically completely determined by the operation parameters of the plastic material mixing, plastic material forming, plastic material divider machines, allows scaling of the disperse system (according to the complete rheological flow curve of the structured systems). Therefore, justification of the parameters of the machine and its design features in 
Justification of the rheological model...

providing and creating the given gradients of velocities and their uniform distribution is the most important task. As a rule, when constructing technological machines and apparatus for confectionery and baked goods, the design features of working bodies were not taken into account or were not given due importance. It resulted in the issue that the machine parameters were mainly determined without taking into account the structural and mechanical properties of the processing systems. The results of the studies on the influence of structural parameters of the machine working body on the speed of formation and change of the structure of the environment confirmed the importance and necessity of taking these factors into accountwhen justifying the optimum parameters of mixing, injection, and setting of the productivity of the machine.

The study of structural and mechanical properties of an elastic-plastic-viscous working substance (Drozdziel, 2016) showed that the productivity of machines is determined mainly by the constructive parameters of the working bodies - geometry, kinematics, and contact area. In addition, in conditions of the continuous process, characterizes the angle of suction and injection, which is ensured by transporting the plastic material in the flow of the working chamber. An important role has the uniform filling of the working chamber with a working substance whose density changes in the process. Uniform filling of the working chamber can also be ensured by changing its volume.

It should also be noted that other factors (Bloksma, Niemann 1975), also have impact on changing the bound mass, such as qualitative indicators of the given environment components; conditions for their storage; temperature parameters of the formation of bound mass; the microclimate of the production premises in which the process takes place. Conducted studies have shown that the best quality of the environment and finished products could be achieved while even filling of the chamber during the entire injection process. Therefore, the main influential factors on the qualitative indicators of the finished product are the structural and mechanical characteristics of the environment mass that is in the working chamber of the machine.

When rollers with grooves conduct mechanical impact (Stadnyk, Novak, Matenchuk, 2018) on structured dispersion plastic material in the injection unit of the molding machine, tangential stresses and shear deformations are predominant. Since tensile defor-mation strain, compression, torsion are present at the injection unit then along with the exter-nal changes of the form, there are changes in the internal location of the particles of the plastic material structure. The permanent change of particles located in the plastic material structure occurs through simple shear deformations. However, this causes not only tangents but also normal stresses that can reach values that exceed the corresponding values of tangential stresses. This phenomenon was first noted by Weissenberg for disperse systems. For a long time (Malkin, Isayev, 2006) it has been the subject of research by various scientists, whose views are considerably different. Based on this, there is a trend in designing aconstruction of the injection node of the molding machine and in justifying the operating modes. When justifying the regimes, it is necessary to ensure the receipt of high-quality semi-finished plastic material with reduced energy costs. Resulting mathematical dependencies will be suitable for engineering calculations of energy costs during the process.

Mechanical influence of the roller-type working bodies and the temperature in the working chamber affects the duration of deformation separate stages. They can change and move, and also converge. While designing the injection unit, one should take into account that at multiple deformations of the plastic material by rollers, pressure in the injection area increas- 
es. Upon the compression, pressure in the dough bulk is distributed unevenly and depends on the duration of the applied force of deformation. Therefore, the rheological properties of the plastic material at injection allow us to determine qualitatively and quantitatively its behavior under the influence of design and technical factors and allow us to link stress-strain during the process of rollers work.

The plastic material deformation behavior can be characterized by the so-called flow curve. This curve is based on experimental data in coordinates: shear stress - shear rate. In general (Nikolaev, 1976), this dependence can be written down as:

$$
\theta=f(\dot{\gamma}), \text { or } \dot{\gamma}=f(\theta)
$$

This equation applies to real systems, which can be either liquids or solid materials. The plastic material shows properties of liquids only after exceeding a critical value by the tangent stress - the marginal shear stress, which determines its plastic properties. It is known that the dough has a spatial structure that creates resistance to strain below the allowable shear stress. At a higher strain, the structure of the plastic material collapses. Since the dough is a dispersed medium with distributed phases, then the suspended particles represent a complex form of diverse nature placed in it. Under the action of rollers, the plastic material gets a stretched form and perceives the shape of the current that induces it to rotate and move along the axis of flow - this condition of the plastic material to the change of viscosity. Particles elastic deformation occurs the change of viscosity. With an ordinary shear, the maximum tensile and compression stress is at an angle to the direction of the shift. Therefore, with the increase of the shear, viscosity increases.

A progress of the shear of elastic-plastic deformations in the plastic material bulk which undergoes deformation and fermentation in the working chamber, reduces its density. The process (Chu, Satas, 1989) takes place under appropriately reduced strains, so the initial modulus of the shear resilient-elasticity and the viscosity of such dough should not be higher than dough that undergoes fermentation. Reducing the dough density at fermentation allows the proteins to exercise more of their elastic properties, so to reduce the modulus of shear resilient-elasticity.

When the time of contact between the plastic material and the roller is very short, the adiabatic compression of air occurs in the load zone due to two reasons:

- the air fails to leave from the porous structure;

- due to plastic material low heat conductivity, the heat exchange between the air in pores and the environment does not occur.

Based on the results of research (Stadnyk, 2016) and conditional reasons, the control over deformation processes is necessary according to the following:

- to limit the amount of heat accumulated by the plastic material, to reduce the thermal stresses;

- to provide the interaction between roller and plastic material with an acceptable energy load to increase the friction properties of their surface layers;

- to set a connection between the rate of deformation processes to interact with the capture and injection angle of the plastic material.

The observation of the effect of the roller on the plastic material allowed to define its biggest stretch within the angle $\varphi$, which values starts from 45 towards the directional shear. 
Justification of the rheological model...

\section{Materials}

The plastic material with the moisture content of $33 \%$, for high-quality wheat flakes on pressed yeast, was prepared in an opaque manner with a fermentation time of 60 minutes at the temperature of $32-33^{\circ} \mathrm{C}$. The quality of the pressed yeast corresponds to the DSTU. Characteristics of wheat flour:

- mass fraction of moisture $(\%)-14,5$,

- the content of raw gluten $(\%)-28$,

- resistance gluten compression on the device IDK-1, per.pril. - 54,

- gluten stretch $(\mathrm{cm})-14$.

\section{Methodology}

Investigation of the process of injection and rollout of the plastic material was carried out on the molding machine B-54 of the confectionery factory (Ternopil) and physical models, created in the department of OCHT (TNTU named after Ivan Puluj). Any of the structural schemes that were developed and existed with the participation of roller working bodies can be mathematically described by equations connected in time with continuous functions. These include geometric dimensions of equipment and characteristics of the working rolls, as well as the properties and physical and mechanical state of the viscous medium, which depends on the conditions of rolling.

Based on the developed approaches for describing the process of injecting plastic material in the gap between the rolls, the hydrodynamic theory of calibration of the pseudoplastic fluid was used. This allows setting (Stadnyk, 2016), (Stadnyk, Grigorowicz Dobrotvor, Szwedziak, 2016) the quantitative dependencies between the geometric characteristics of the working space (gap) and the properties of materials and processing modes. With the use of this process theory, number of formulas have been developed to determine the pressure in the gap between the rolls, based on the parameters and viscosity of the medium.

Characteristics of the plastic material with the indestructible structure were investigated by the device RV-8. Experiments are carried out at small shear forces, the magnitude of which is less than the marginal shear stress. Every 10-20 seconds, the deformation values indicated by the arrow deviation are registered. Knowing the geometric characteristics of the device and measurement data, the shear stress is calculated :

$$
\tau^{\prime}=\tau-\tau_{\kappa}=\frac{\left(m-m_{0}\right) g R_{u \kappa}}{2 \pi R_{6}^{2} h_{n p}}
$$

where:

$\mathrm{m} \quad-$ the weight of the load that rotates the rotor. It consists of a mass of two weights and masses of cups,

$\mathrm{kg} \quad-\quad$ (except for the value compensating friction in the bearings),

$\mathrm{m}_{0} \quad-\quad$ is the mass of the load in which the rotor starts to rotate. Accordingly, (Machihin U., 1991) plastic viscosity was determined:

$$
\mu_{n l}=\left(\tau-\tau^{1}\right) / \gamma
$$




\section{Results and Discussion}

Taking into account the above, based on the analysis of the interaction of rollers with yeast plastic material, we have designed and developed a new design for the injection unit (Fig. 1). At first glance, this unit has all the design parameters that do not differ from the existing ones. The main difference is the design parameter, and the geometry of the rollers surface, the method of the plastic material dragging and injection, keeping particles at a permanent state at the plastic material structure due to ordinal shear deformations. Our approach allowed keeping and perceiving such a form of plastic material flow which induces the movement along the axis without additional heat release, reducing viscous friction.

Let us consider the main parameters of the process and their impact on it. The plastic material after kneading resists multiple deformations, so the transformation of its mass into the strip occurs by passing through rotating rollers of the molding machine. During multiple deformations dough which is under the influence of a mechanical action of the rollers, faces shear and compression deformation. As a result, there are longitudinal and transverse stresses in the plastic material, which are accompanied by extension and expansion of the plastic material layer. The plastic material bulk takes, in the same way, the deformation of compression and stretching. The air pressure will not be uniform in the plastic material and not evenly distributed in its bulk. At the plastic material output from the rotating rollers, the compression rate is almost homogeneous, since there is a maximum contact of their surfaces.

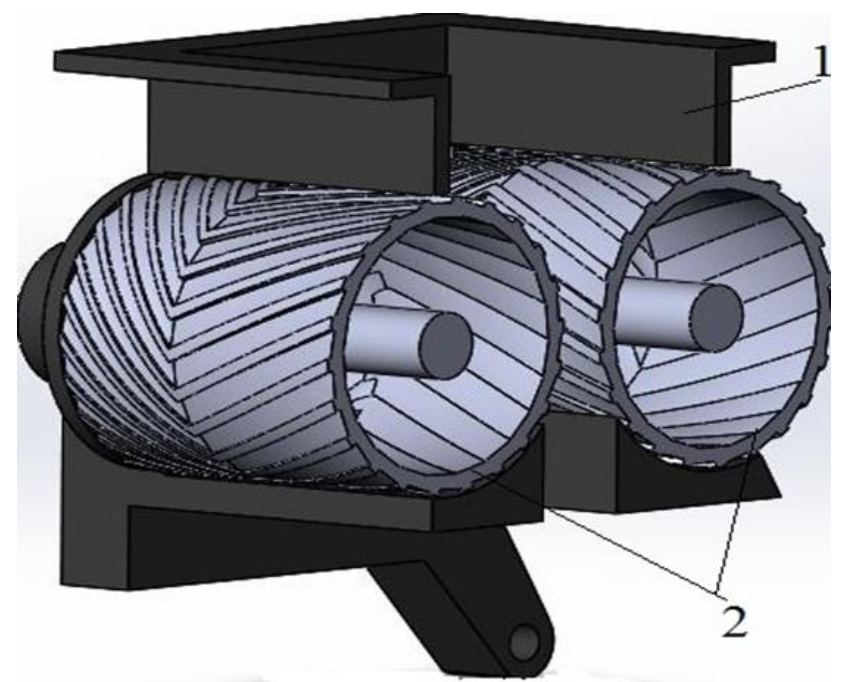

Figure 1. Cross-section of the injection unit: 1 - working chamber; 2 - spiral rollers

Mostly longitudinal stresses arise in the plastic material when it is injected with the same sequence of directed deformation, and that results in the stretch of the plastic material layer. The stresses that appear at the same time are distributed evenly over the plastic material bulk, 
Justification of the rheological model...

and the deformation will occur equally in the length and width of its formed shape in the gap between the rollers.

The homogeneous mathematical model cannot describe all the processes as mentioned above at the loading of plastic material by rotating rollers. It is impossible to provide the same conditions for yeast plastic material. Therefore, it is necessary to generalize the experimental studies of its injection.

Under the action of the external force on plastic material in it, there is a proper re-action of two forces of operating parallel each other:

The relevant reaction of two forces acting parallel to each other under the action of external force on the plastic material:

$$
\mathrm{F}=\mathrm{F} 1+\mathrm{F} 2
$$

where:

F1 - is the strength of the plastic material resistance to deformation,

F2 - is the elastic force that occurs at the adiabatic compression of air.

Due to the permanent formation of carbon dioxide and an increase of volume in this way, the plastic material that continues fermentation in the working chamber of the injection unit differs from the plastic material which does not ferment because it is a two way stressed system. The gravitational forces of its bulk during fermentation are inferior to the developing power that forms and moves the gas bubbles according to Stokes's law (spherical bodies moving through a viscous medium) - as a result of the mathematical processing of experimental data, the flow curve of bagel yeast plastic material, presented in Fig. 2 was obtained.

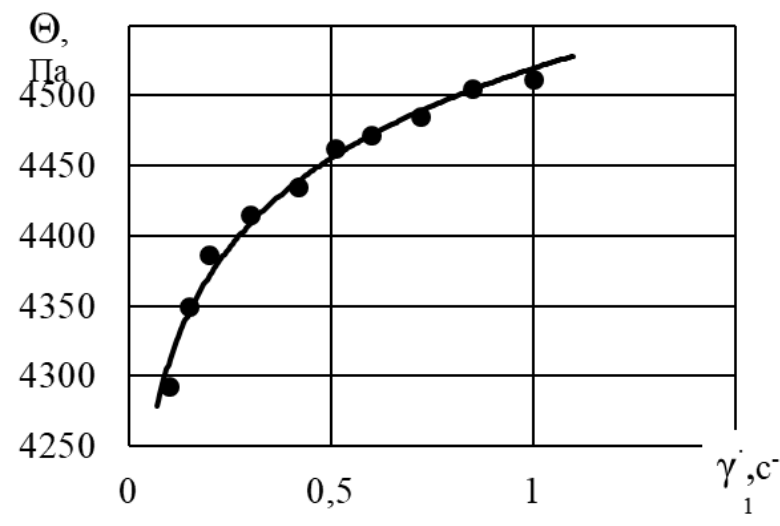

Figure 2. Dependence of the shear stress against shear rate

The obtained dependence characterizes a behavior of the plastic material and has a powerlaw nature with the equation form:

$$
\theta=4520 \cdot \gamma^{0.02}
$$


Today, there are no methods that can completely exclude fermentation from the technological scheme of bagels production. Strengthened mechanical processing of the plastic material by the rollers and molding devices do not provide the desired quality of finished products. Therefore, maintenane of all essential reactions which take place during fermentation, subject to replacing the injecting rollers, is the relevant issue in the new design of the unit. At the same time, the loss of dry substance is also reduced.

Experimental data (Stadnyk, 2018) showed that increasing the pressure in the plastic material causes a significant decrease in its volume. The relationship between pressure and volume is nonlinear. The largest volume change takes place at the initial stage of deformation and decreases over the processing time during the transition to the maximum pressure. As a result of the mathematical processing of the data of compression of the bagel yeast plastic material, an empirical equation is obtained:

$$
p V^{x}=b \cdot 10^{c}
$$

where:

p $\quad-$ pressure, $(\mathrm{MPa})$

$\mathrm{V}$ - volume of the plastic material in the working chamber, $\left(\mathrm{cm}^{2}\right)$

$\mathrm{x}, \mathrm{b}, \mathrm{c}-$ imperial coefficients at the gas phase of $6.65 \%$, they arrange: $36.4 ; 0.78 ; 49.8$; at $12 \%-18.1 ; 0.18 ; 26.7$.

The indicator of the plastic material degree is greater when the less is the gas phase, which follows from the analysis of the equation. Consequently, the compression of the plastic material is driven by the gas phase and deformation of the structural grid of the plastic material. Therefore, at the initial stage of the tightening of the plastic material by the rollers during compression, there is dispersion of gas bubbles and their compression. With the subsequent influence of the rollers, diffusion of bubbles into the dough, bulk occurs. When deformation is reduced, dissolved gas begins to squirt out from the whole plastic material bulk, which furthers its increase. It should also be noted that, for the same pressure, the amount of squirted gas is less than at the compression period. A constant increase of the gas bubbles after rmoval of deformation lasts $1.6 \mathrm{~s}$ and is due to fermentation of the plastic material.

The temperature is one of the important factors affecting the rheological properties of the plastic material. The nature of the temperature change affects the change in viscosity, which allows, to some extent, control of the technological process of identifying the optimal modes of the injection unit operation. The rheological properties of bagel dough according to the study of many authors (Nikolaev 1976, Stadnyk, 2013) point to linkages of viscosity, acceptable shear stress, modulus of shear elasticity and the module of plasticity. As the temperature rises, their properties decrease. The viscosity dependence on the temperature for the injection unit is expressed by the ratio of the viscosity difference at two different temperatures to the difference between these temperatures:

$$
\frac{\eta t_{1}-\eta t_{2}}{t_{2}-t_{1}}
$$

It follows from the dependence that, with a small temperature change, the injection of the plastic material by the rollers leads to significant fluctuations in the viscosity and other physicomechanical characteristics. Simultaneous increase of shear rate at all temperatures leads to a decrease in viscosity. Accordingly, it results in a decrease in the absolute value of the 
Justification of the rheological model...

difference between the viscosities at two different temperatures. Analytical dependence between viscosity and temperature has been developed by Le Chatelier. The following equation can be used to determine viscosity:

$$
\eta_{\mathrm{T}}=\mathrm{e}^{\frac{\mathrm{A}}{t^{B}}}
$$

where:

$\mathrm{t} \quad-$ is the temperature, $\left({ }^{\circ} \mathrm{C}\right)$

A and B - constants obtained experimentally, and which depend on the shear rate.

The effective viscosity, obtained by the complete rheological curve, is considered to be the main characteristic of the structural and mechanical properties of disperse systems. The dependence of the effective viscosity on the shear rate gradient is shown in Fig. 3

Effective viscosity decreases with an increase of the shear rate. This is due to the orientation of the high-molecular compounds of the plastic material in the movement direction of the increasing shear forces.

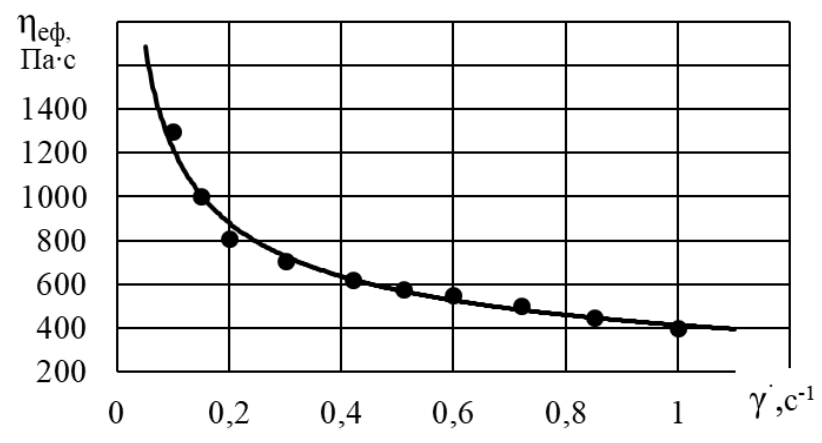

Figure 3. Dependence of effective viscosity on shear rate

The mathematical expression of the function:

$$
\eta_{\mathrm{e \phi}}=415 \cdot \gamma^{-0,47}
$$

Increasing the shear rate leads to a decrease in viscosity, which is typical for the plastic material, in which the orientation of the molecules towards the shear direction and the disintegration of the ties between them occurs during the deformation.

The methods of physicochemical mechanics allow identification of the relationship between the properties of the plastic material and the technological control of the injection process. The analysis of the study showed the possibility of establishing the relationship between all deformations occurring at injection (in the working chamber of the injection unit), to determine the rheological model of the process. The study of the effective viscosity of the plastic material nef, depending on the action of the shear stress $\mathrm{Q}$, the velocity gradient $\mathrm{g}$, as well as the flow velocity (productivity Q), allows us to determine the rheological behavior of the 
plastic material under the effect of the designed rollers of the injection unit. Hence to determine the nature of the destruction of the plastic material structure and optimal modes of its deformation (tightening, compression, injection, pumping).

Studies have shown that, regardless of the kind of flour from which the plastic material for bagels is prepared, its moisture $\mathrm{W}$ and the duration of fermentation, the effective viscosity of the plastic material nef decreases with the increase of the shear stress. Therefore, adeformation behavior of the dough in the injection unit of the developed design can be described by the sum of three components: elastic deformation, permanent deformation, and highly elastic deformation. The mentioned is reversed to the direction of stress, the second is irreversible, and the third one is the inverse, where its relaxation passes with a delay in time. The most relevant features of the mechanical behavior of the plastic material were found at the action of rollers with a discrete constant rate of deformation. In this mode, the stability of the dough is compared with the existing rollers. This is due to the influence of the boundary conditions and the presence of frictional forces on the surfaces of rollers.

In the area of elastic deformations of the plastic material in the new injection, the unit is due to the stability of the homogeneity of the stress and deformation field which in turn due to the choice of the surface of the rollers and their contact with the dough bulk and the duration of the cycles.

Based on the considered and conducted researches, we have developed an updated rheological model (see Fig. 4). As the deformation of the Bingham body evolves instantly; therefore, our equation has the following form:

$$
\begin{gathered}
\frac{3}{G} * \dot{\theta}+\left(\frac{1}{\eta}+\frac{2}{\eta_{\mathrm{pl}}}\right) * \theta=\frac{2 \theta_{T}}{\eta_{\mathrm{pl}}} \\
\theta=u v, \dot{\theta}=\dot{u} * v+u \dot{v}
\end{gathered}
$$

The velocity of transmission of the elastic deformation in the plastic material is at the same time function of stresses and temperatures that are close to the exponential. Integration of equation (9) gives us:

$$
\begin{gathered}
\frac{3}{G}(\dot{u} * v+u * \dot{v})+\left(\frac{1}{\eta}+\frac{2}{\eta_{\mathrm{pl}}}\right) * u v=\frac{2 \theta_{T}}{\eta_{\mathrm{pl}}} \\
\frac{3}{G} \dot{u} * v+u\left(\dot{v}+\left(\frac{1}{\eta}+\frac{2}{\eta_{\mathrm{pl}}}\right) * v\right)=\frac{2 \theta_{T}}{\eta_{\mathrm{pl}}} \\
\frac{d v}{d t}=-\left(\frac{1}{\eta}+\frac{2}{\eta_{\mathrm{pl}}}\right) * v \\
\int \frac{d v}{v}=-\int\left(\frac{1}{\eta}+\frac{2}{\eta_{\mathrm{pl}}}\right) d t \\
\ln |v|=\left(\frac{1}{\eta}+\frac{2}{\eta_{\mathrm{pl}}}\right) * t \\
v=e^{-\left(\frac{1}{\eta}+\frac{2}{\eta_{\mathrm{pl}}}\right) * t}
\end{gathered}
$$


Justification of the rheological model...

$$
\begin{gathered}
\frac{3}{G} * \frac{d u}{d t} * e^{-\left(\frac{1}{\eta}+\frac{2}{\eta_{\mathrm{pl}}}\right) * t}=\frac{2 u_{T}}{\eta_{\mathrm{pl}}} \\
\frac{d u}{d t}=\frac{2 \theta_{T}}{\eta_{\mathrm{pl}}} * \frac{G}{3} * e^{-\left(\frac{1}{\eta}+\frac{2}{\eta_{\mathrm{pl}}}\right) * t} \\
u=\frac{2}{3} \frac{\theta_{T} G}{\eta_{\mathrm{pl}}} \int e^{-\left(\frac{1}{\eta}+\frac{2}{\eta_{\mathrm{pl}}}\right) * t_{0} / T} \\
u=\frac{2}{3} \frac{\theta_{T} G}{\eta_{\mathrm{pl}}} * \frac{\eta \eta_{\mathrm{pl}}}{\eta_{\mathrm{pl}} 2 \eta} e^{-\left(\frac{1}{\eta}+\frac{2}{\eta_{\mathrm{pl}}}\right) * t}+C \\
u=\frac{2}{3} \frac{\theta_{T} G}{\eta_{\mathrm{pl}}+2 \eta} * \eta * e^{-\left(\frac{1}{\eta}+\frac{2}{\eta_{\mathrm{pl}}}\right) * t}+C \\
\theta_{(t)}=\frac{2}{3} \frac{\theta_{T} G \eta}{\eta_{\mathrm{pl}}+2 \eta}+C * e^{-\left(\frac{1}{\eta}+\frac{2}{\eta_{\mathrm{pl}}}\right) * t}
\end{gathered}
$$

This equation shows the relationship between the initial dough deformation at the initial moment $(t=0)$ with stress during permanent deformation and plastic material viscosity, which partially changes. From the equation, it can be seen that with the increase of the elastic modulus $\mathrm{G}$, the deformation increases and asymmetrically approaches the value of viscosity. Therefore, the deformation of the plastic material does not grow immediately but is delayed due to its elastic forces. The value $\mathrm{G}$ characterizes the rate of deformation and can be as the coefficient of the process driving force. The component of the expression does not have a significant effect on the process since its value is quite small. When changing boundary, the shear stresses that characterize the strength of the plastic material spatial structure, there is a slow flow. In case of such a slow flow, the structure is partially destroyed but keeps pace with recovery. The equilibrium degree of the disruption of the structure in such a slow stationary flow is quite small. Such a nature of the plastic viscosity of the plastic material change, independence of the shear rate, indicates the presence of internal links, which determine the structure formation. The mechanical model is proposed based on the rheological model (Fig. 4). 


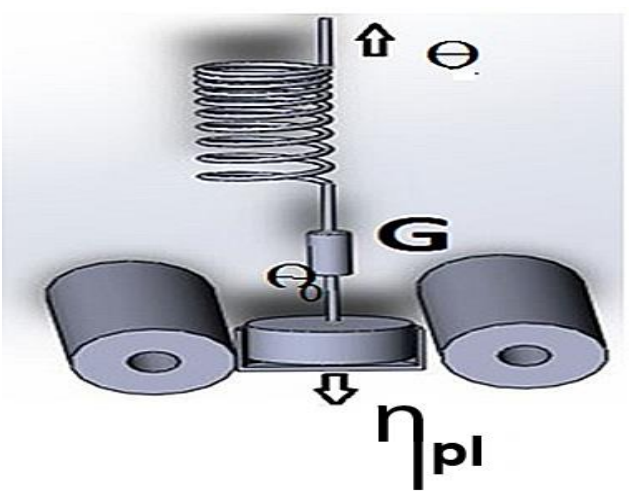

Figure 4. Mechanical rheological model of the plastic material at injection

A model differs from the Bingham body in that parallel to the Saint-Venant body the Maxwell body is present. Such a relationship shows the uniformity of elastic and viscous elements during deformation of the plastic material. The flow non-linearity is due to the change in viscosity and depends on the shear rate of elastic deformation. Such frequent deformation changes are constantly transmitted to the plastic material, which causes an increase in dissipation energy. Therefore, when the shear rate increases the viscosity also increases.

\section{Conclusions}

Plastic material tries to restore its original form. The rollers design affects the viscosity decrease and the plasticity increase of the plastic material.

The influence of the roller surface provides with a uniform distribution of air, and the air surplus is removed, the plastic material acquires a fine porous structure due to this. Material is the most plastic at the injection when its temperature is close to the temperature of the kneading temperature. The distinctive gloss appearing on the surface of the product is mainly due to the the rollers (Fig. 5).

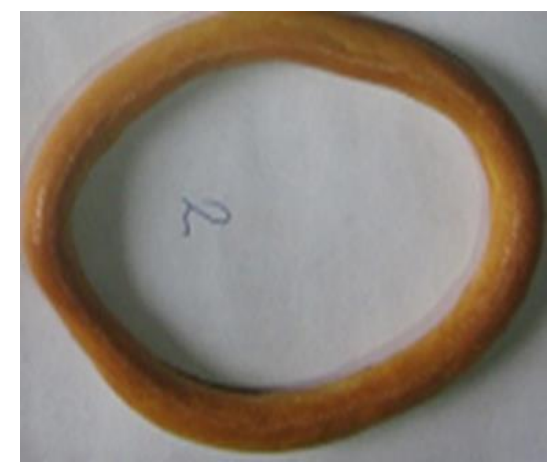

Figure 5. The general look of the bagel 
Justification of the rheological model...

The proposed rheological model is able to describe adequately the behavior of the yeast plastic material under the action of the rollers, taking into account the existence of the boundary shear stress of the material and the dependence of its viscosity on the deformation rate, while being mathematically simple and having a minimum number of parameters for engineering calculations.

\section{References}

Bloksma, A. H. (1990). Dough structure, dough rheology, and baking quality. Cereal Foods World, 35(2), 237-244.

Bloksma, A., Niemann, W. (1975). The effects of temperature on some rheological properties of wheat flour doughs. Journal of Texture Studies, vol. 6, no. 3, pp. 343-361. DOI: https://doi.org/10.1111 /j.1745-4603.1975.tb01130.x

Chu, S.G. (1989). In D. Satas, Handbook of pressure-sensitive adhesive technology, Chapter 8. New York: Van Nostrand Reinhold.

Drozdziel, P., Derkach, A., Stadnyk, I., Vitenko, T. (2016). Simulation of components mixing in order to determine rational parameters of working bodies. Advances in Science and Technology Research Journal, Vol. 9, pp.130-138, https://doi.org/10.12913/22998624/64068

Daniłowicz Stadnyk, P., Grigorowicz Dobrotvor, I., Szwedziak, K. (2016). Determination of power output and impact on the rheological parameters of raw materials during rolling, Agricultural Engineering. Vol. 20, No.2, pp.135-142. DOI: 10.1515/agriceng-2016-0035.

Machihin, U. (1991). Engineering rheology of food materials. p.23-59, Light \& Food Industry, 216.

Malkin, A.Y., Isayev A.I. (2006). Rheology: conception, methods, application. ChemTec Publishing, Toronto, pp. 474.

Nikolaev, B. (1976). Measuring of structural and mechanical properties of flour dough. P.83-127.- M.: Food Industry, $246 \mathrm{pp}$.

Shurchukova, U., Radchenko, O. (2013). Theoretical study of hydrodynamic and heat transfer processes occurring in the channel of the prematrix and matrix zones of the extruder. Scientific Works of Odessa National Academy of Food Technologies. Vol. 43, No. 2, pp. 7-10. Available at: http://nbuv.gov.ua/UJRN/Np_2013_43\%282\%29_4 
K. Szwedziak, I. Stadnyk, S. Golyachuk, Ż. Grzywacz

\title{
UZASADNIENIE REOLOGICZNEGO MODELU PROCESU WTRYSKU MATERIAŁÓW Z TWORZYWA SZTUCZNEGO PRZEZ ROLKI
}

\begin{abstract}
Streszczenie. Jest uzasadnione, że problemy zmiany właściwości konstrukcyjnych i mechanicznych materiału plastycznego oraz wpływu na nie elementów konstrukcyjnych sprzętu i sposobów realizacji procesu formowania są rozpatrywane w kompleksowo, biorąc pod uwagę dane empiryczne, zależności teoretyczne i wyniki ek-sperymentów fizycznych. Ustalono, że podczas mechanicznego wpływu rolek z rowkami na ustrukturyzowany materiał dyspersyjny plastyczny w węźle wtrysku maszyny do formowania, ścinanie wewnętrzne i odkształcenie ścinające mają przewagę. W związku z tym wydajność maszyn zależy głównie od parametrów kon-strukcyjnych geometrii ciał roboczych, kinematyki i powierzchni styku. Pokazano, że zwiększenie ciśnienia w materiale plastycznym powoduje zmniejszenie jego objętości, ale związek między ciśnieniem i objętością ma charakter nieliniowy. Ustalono, że bez względu na różnorodność mąki, z której przygotowano materiał plastyczny na bułec-zki, jego wilgotność i czas trwania fermentacji zmniejsza lepkość efektywnego tworzywa sztucznego wraz ze wzrostem naprężeń ścinających $W$ artykule opisano wyrafinowany model reologiczny deformacji ciała Binghama, która rozwija się natychmiast, a prędkość wspólnej deformacji sprężystej w cieście jest jednoczesną funkcją naprężeń i temperatur, które są bliskie wykładniczym.
\end{abstract}

Słowa kluczowe: medium trójfazowe, wałki, reologia, odkształcenie przesuwne, materiał plastyczny, faza gazowa 